\title{
Technical Note: Validation of a System for Monitoring Individual Feeding and Drinking Behavior and Intake in Group-Housed Cattle
}

\author{
N. Chapinal, ${ }^{*}$ D. M. Veira,† D. M. Weary, ${ }^{*}$ and M. A. G. von Keyserlingk*1 \\ *Animal Welfare Program, The University of British Columbia, 2357 Main Mall, Vancouver V6T 1Z4, Canada \\ †Pacific Agri-Food Research Centre, Agriculture and Agri-Food Canada, PO Box 1000, Agassiz, British Columbia V0M 1A0, Canada
}

\begin{abstract}
The objective of this study was to validate a system for monitoring individual feeding and drinking behavior and intake in group-housed cattle. A total of 42 Holstein cows were tested with access to 24 feed bins and 4 water bins. For the purposes of this validation experiment, we focused our observations on 4 water bins and 13 feed bins. When the cow approached the feed or water bin, an antenna detected the cow's unique passive transponder and lowered the barrier, allowing the cow access to the feed or water. For each visit to the bin, the system recorded the cow number, bin number, initial and final times and weight and calculated the visit duration and intake. Bins were also monitored by direct observation and time-lapse video recording for $2 \mathrm{~d}$ per bin, with observations for 4 and $6 \mathrm{~h} / \mathrm{d}$ for the feed and water bins, respectively. Data from direct observations were compared with the electronic data recorded by the system. Feed disappearance over $24 \mathrm{~h}$ was assessed by using an external scale over 3 consecutive 24 -h periods, and these values were compared with the sum of intakes across all visits to that bin for the same time periods. The system showed a high specificity (100\%) and sensitivity (100 and $99.76 \%$ for the feed and water bins, respectively) for cow identification. The duration of the feeding and drinking visits and the feed and water intake per visit, as estimated by the monitoring system, were highly correlated with those obtained by direct observation $\left(R^{2} \geq 0.99\right.$ in all the cases). The comparison of the total feed that disappeared from each bin in $24 \mathrm{~h}$ with the sum of the feed cows consumed from that bin during the same period differed by less than $1 \mathrm{~kg}$ (29.92 \pm $0.90 \mathrm{~kg}$ and $29.24 \pm 0.90 \mathrm{~kg}$ as estimated by manual weighing and by the electronic system, respectively). This difference could be attributed to changes in feed moisture during the 24 -h period. In conclusion, this
\end{abstract}

Received May 2, 2007.

Accepted August 19, 2007.

${ }^{1}$ Corresponding author: nina@interchange.ubc.ca electronic system is a useful tool for monitoring intakes and feeding and drinking behavior of loosehoused cows.

Key words: feeding behavior, dairy cow, validation

Traditional nutrition research in dairy cattle has focused on assessing the relationship between DMI and production (e.g., Grant and Albright, 1995). The majority of this research has been with animals housed in tie stalls (e.g., Mulligan et al., 2002) or group housed but trained to access a particular feed bin so that each animal's daily feed intake can be monitored (e.g., Daniels et al., 2006). These methods for collecting individual intake may not accurately reflect the intakes of cows housed in groups, where they need to compete for access to food (DeVries and von Keyserlingk, 2006; Huzzey et al., 2006).

Feeding behavior is often thought to provide some indication of how much cows are eating (e.g., Murphy, 1992; Nielsen, 1999), and drinking behavior may also be a useful predictor of both water and feed intake. Unfortunately, monitoring feeding and drinking behavior in loose-housed cows is also difficult. Traditionally, these behaviors have been monitored through direct observation or time-lapse video recording (Friend et al., 1977; Vasilatos and Wangsness, 1980; Huzzey et al., 2005), both of which are labor intensive. More recently, electronic systems for monitoring feeding behavior have been developed and validated (e.g., DeVries et al., 2003).

The Insentec monitoring system (Insentec, Marknesse, the Netherlands) provides measures of feed and water intake (e.g., Tolkamp et al., 2000; Huzzey et al., 2007) and allows researchers to collect continuous feeding and drinking behavioral data for loose-housed cows that can freely access a number of feeding and drinking stations. However, to date no data have been published that validate either the behavioral measures or intakes from this system. Thus, the objective of this study was to validate these measures by comparing estimates collected electronically with those from direct human observation and time-lapse video recordings. 
A total of 42 Holstein cows at The University of British Columbia Dairy Education and Research Center (Agassiz, British Columbia, Canada) were tested with access to 24 feed bins and 4 water bins. Each individual feed bin was $1.00 \mathrm{~m}$ wide, $0.75 \mathrm{~m}$ high, and had a depth of $0.84 \mathrm{~m}$. Each feed bin was assigned to either a single cow or multiple cows. Feed bins could hold approximately $40 \mathrm{~kg}$ as-fed TMR. Individual water bins were identical in size to that described above, and all cows had access to the water bin. The water bins were programmed to hold $40 \mathrm{~kg}$ of water and were refilled after each visit, provided cows had drunk at least $1 \mathrm{~kg}$. Each cow was fitted with an ear tag containing a unique passive transponder (High-Performance ISO Half Duplex Electronic ID Tag, Allflex Canada, St-Hyacinthe, Quebec, Canada). When the cow approached the feed or water bin, an antenna detected the cow's transponder and lowered the barrier, allowing the cow access to the feed or water. When the cow finished eating or drinking and left the bin, the barrier would close until the next cow approached. For each visit to the bin, the system recorded the cow number, the bin number, the initial and final times and weight and calculated the duration and intake. For the purposes of this validation experiment, we focused our observations on 4 water bins and 13 feed bins. During the course of the experiment, prepartum cows were fed a close-up TMR consisting of $21.3 \%$ corn silage, $42.8 \%$ alfalfa hay, and $35.9 \%$ concentrate and mineral mix on a DM basis (DM: $50.8 \pm 1.19 \%$; CP: $14.4 \pm 1.01 \%$ of DM; ADF: $35.0 \pm 2.74 \%$ of DM; NDF: $45.6 \pm 2.57 \%$ of $\mathrm{DM}$; and $\mathrm{NE}_{\mathrm{L}}: 1.40 \mathrm{Mcal} / \mathrm{kg}$ ). Lactating cows were fed a TMR consisting of $21.3 \%$ grass silage, $14.7 \%$ corn silage, $12.3 \%$ alfalfa hay, and $51.7 \%$ concentrate and mineral mix on a DM basis (DM: $51.1 \pm$ $1.82 \%$; CP: $17.7 \pm 1.00 \%$ of DM; ADF: $23.7 \pm 1.42 \%$ of $\mathrm{DM}$; NDF: $36.1 \pm 1.82 \%$ of DM; and $\mathrm{NE}_{\mathrm{L}}: 1.66 \mathrm{Mcal} /$ $\mathrm{kg})$. Fresh feed was provided at 0600 and $1600 \mathrm{~h}$. Video cameras (Panasonic WV-BP330, Panasonic, Osaka, Japan) monitored the feed bins and water bins, and were connected to a video multiplexer (Panasonic WJ-
FS216) and a time-lapse videocassette recorder (Panasonic AG-6540). The clocks on the video recorder and the computer collecting the data were synchronized. Cows were individually identified with ear tags and with symbols dyed onto both sides of their bodies.

Trained observers monitored 2 bins/d per person, beginning immediately after the delivery of fresh feed and continuing for $4 \mathrm{~h}$ for feed bins and $6 \mathrm{~h}$ for water bins. In this way, each of the bins was followed for a total of $2 \mathrm{~d}$. For each visit, the observer recorded the cow's ear tag. The observer also recorded the weight of water or feed consumed by using the digital display of the bin. The time that the cow entered and left the bin was assessed by using the video recordings. The start and end times of the visit were assessed by using the opening and closing of the feed barrier.

Feed disappearance over $24 \mathrm{~h}$ was assessed manually during 3 consecutive 24 -h periods by using a digital scale and subtracting the weight of any orts remaining in the bin the next morning from the amount of feed provided the previous day. This value was then compared with the sum of feed disappearances across all the visits to that bin for the same time period.

For all measures, we calculated sensitivity (likelihood that a cow present at the bin is detected as present by the monitoring system) and specificity (likelihood that a cow that is absent from the bin is detected as absent by the monitoring system). All the statistical analyses were conducted with SAS software (SAS Institute, 1999). Measures of duration and feed and water intake per visit generated by the electronic monitoring system (dependent variables) were regressed onto those from direct observation (independent variables), testing for slope and intercept effects. Feed disappearance assessed manually was compared with the sum of feed disappearances across all the visits recorded by the electronic monitoring system by using a mixed model, where the method of obtaining the data (manual vs. electronic) was treated as a fixed effect and the bin as a random effect.

Table 1. Least squares means $\pm \mathrm{SE}$, maximum and minimum value for feeding and drinking visit duration (s), and intake per visit (kg) estimated by electronic and direct observations and regression equation and coefficient between the 2 recording methods, for a total of 665 visits to 13 feed bins and 268 visits to 4 water bins

\begin{tabular}{|c|c|c|c|c|c|c|c|c|}
\hline Item & \multicolumn{3}{|c|}{ Electronic observations } & \multicolumn{3}{|c|}{ Direct observations } & \multicolumn{2}{|c|}{ Regression ${ }^{1}$} \\
\hline \multicolumn{9}{|l|}{ Feeding visits } \\
\hline Intake, kg & $0.8 \pm 0.04$ & -0.1 & 6.6 & $0.8 \pm 0.04$ & 0.0 & 6.6 & $y=x$ & 1 \\
\hline \multicolumn{9}{|c|}{ Drinking visits } \\
\hline Duration, s & $78.3 \pm 3.45$ & 2.0 & 269.0 & $79.7 \pm 3.45$ & 4 & 270.0 & $y=x-1.35$ & 1 \\
\hline
\end{tabular}

${ }^{1} \mathrm{x}=$ direct observations; $\mathrm{y}=$ electronic observations. 
During the observation periods, both the electronic system and direct observation detected a total of 819 visits to the feed bins and 274 visits to the water bins. However, 2 of the visits to the water bins were unusual: on both occasions one cow was displaced by another at the bin, without the barrier raising and dropping between cows. The intruding cow was pushed out of the bin when the barrier raised after 5 and 12 $\mathrm{s}$, respectively, but in neither case was the identity of the intruding cow recorded by the monitoring system. Instead, a single visit was recorded by the electronic system, with the combined visit duration and intake allocated only to the initial cow. Therefore, sensitivity was $100 \%$ for the feed bins but $99.76 \%$ for the water bins, and specificity was $100 \%$ for both the feed and water bins. Other systems that monitor visits to the feeder have recorded slightly lower values. DeVries et al. (2003) described an electronic feeding behavior system that monitored cow presence at the feeding area every $6 \mathrm{~s}$, and reported a sensitivity and specificity of 87.7 and $99.2 \%$, respectively. Bach et al. (2004) described a computerized system for monitoring feeding behavior and individual feed intake consisting of load cells located in front of individual self-locking stations, and reported a sensitivity and specificity of 99.6 and $98.8 \%$, respectively.

The electronic system provided measures of feeding and drinking behavior and feed and water intake that were similar to those recorded by direct observation (Table 1). For these analyses, we discarded data from $1 \mathrm{~d}$ for 4 feed bins because of problems with the video recordings. Our final data set included 665 feeding

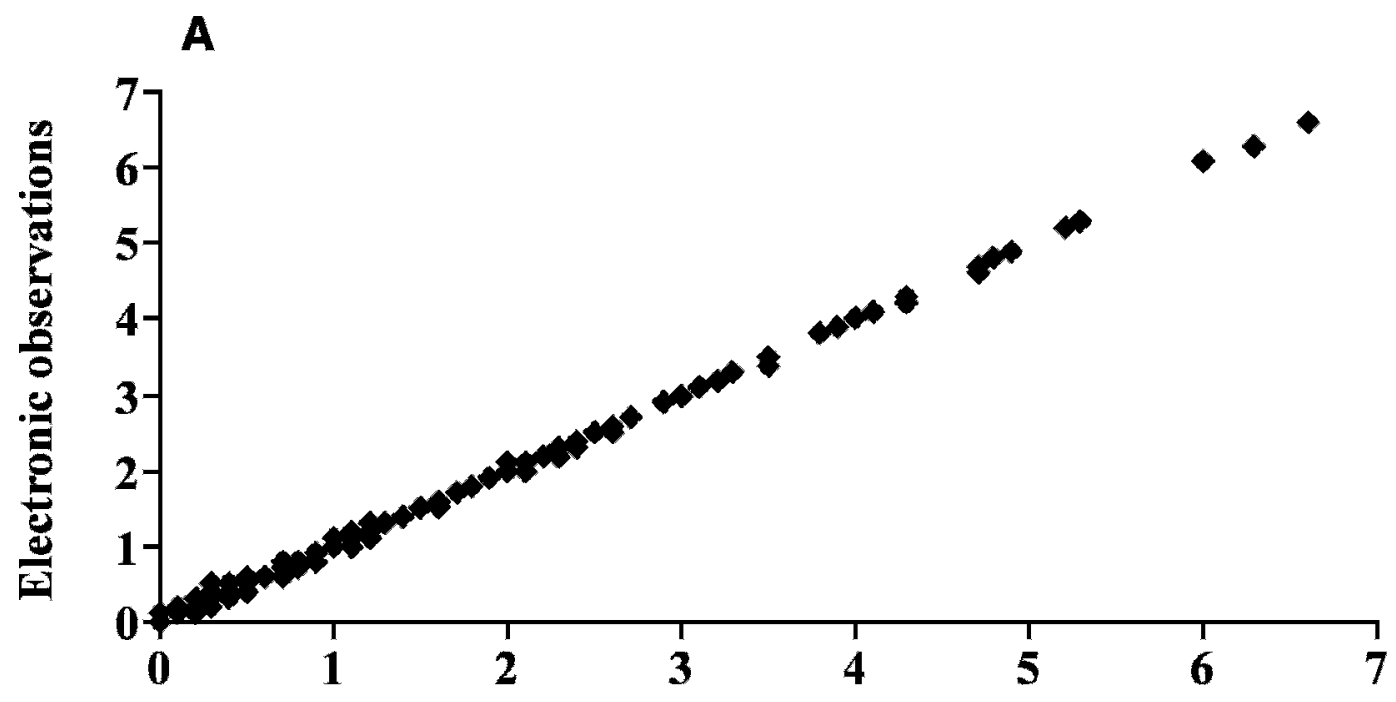

B

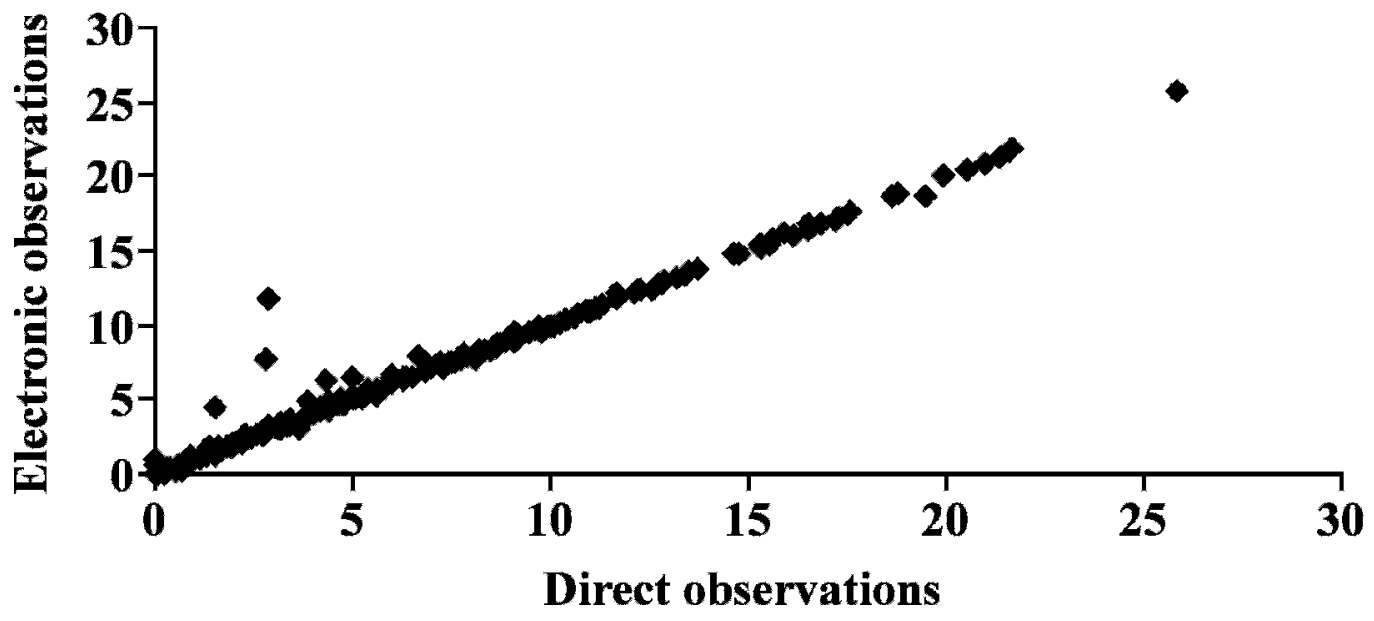

Figure 1. Relationship between the feed (A) and water (B) intake per visit (kg) obtained from the electronic observations and the direct observations for a total of 665 visits to 13 feed bins and 268 visits to 4 water bins. 
visits and 268 drinking visits for which we had electronic and direct observations. The resulting coefficients of determination were significant $(P<0.001)$, and slopes did not differ from $1(P>0.2)$ for all measures tested. The intercept was greater than $0(P<$ 0.05 ) for all measures except the feed intake per visit. In all cases, the direct observations of visit duration were close to $1 \mathrm{~s}$ longer than the value recorded by the electronic monitoring system. The electronic system defined the start and end of the visit on the basis of the transponder coming within range of the antennae located at the top of the feeder. In contrast, visit durations during direct observations were assessed by using opening and closing times of the feed barrier. There was a slight delay between the time a cow withdrew her head from the feeder and the barrier closing, accounting for the slightly longer visit duration assessed by direct observation. These differences were smaller than that found by Bach et al. (2004), and the regression coefficient was slightly higher than that calculated for the meal duration (not calculated in this study) by DeVries et al. (2003).

In one visit to the feed bins and 5 visits to the water bins, negative values were recorded for intake by the electronic monitoring system. These negative values were always small $(-0.1 \mathrm{~kg})$, and were likely due to slight instabilities in the scales, because in all the cases but one visit to the water bin, intakes were recorded as 0 by the direct method. The higher frequency of negative values for the water bins may have been due to wave motion within the bin. The concordance between estimates of intake from the direct and automated methods was lowest when water intakes were low $\left(\mathrm{R}^{2}=0.27,0.49,0.93\right.$, and 1.00 for the first to fourth quartile intakes). The few outlying values in water intake (Figure 1) were likely due to human error during direct observation. The water bins automatically refilled after visits with intakes greater than 1 $\mathrm{kg}$, making observations on these bins more difficult than those on the feed bins. During observations, only one cow was observed pushing feed out of the bin and onto the floor, suggesting that this is not a frequent source of error in estimates of intake from these bins.

The comparison of the total feed that disappeared in $24 \mathrm{~h}$ with the sum of bin visit intakes recorded electronically over the same period differed by $0.68 \mathrm{~kg}$ $(29.92 \pm 0.90 \mathrm{~kg}$ and $29.24 \pm 0.90 \mathrm{~kg}$ as estimated by manual weighing and by the electronic system, respectively). This difference could be partially attributed to changes in feed moisture during the 24-h period. In any case, the visits were short enough that intake per visit recorded by the monitoring system was not affected by moisture changes. Thus, the electronic recording of intake on a per-visit basis is likely a more accurate measure of wet feed intakes, although DMI may be better estimated by using 24 -h feed disappearance.

In conclusion, the electronic system described herein is a useful tool for monitoring intakes and feeding and drinking behavior of loose-housed cows. The system provides reliable estimates of the number of visits per animal, duration of each visit, intake per visit, and therefore feeding and drinking rate, total time spent in the feed and water bins daily per animal, and total amount of feed and water consumed daily per animal.

\section{ACKNOWLEDGMENTS}

We gratefully acknowledge the staff and students at The University of British Columbia's Dairy Education and Research Centre and the University's Animal Welfare Program, and especially Audrey Nadalin and Gabi Krisinger for their help with the live observations. The equipment described in this study was purchased, in part, by a grant awarded to M. A. G. von Keyserlingk by the Canadian Foundation for Innovation and the British Columbia Knowledge Development Fund. The project was funded by the Natural Sciences and Engineering Research Council of Canada, through the Industrial Research Chair in Animal Welfare, and by contributions from the Dairy Farmers of Canada, the British Columbia Dairy Foundation, members of the British Columbia Veterinary Medical Association, and many other donors listed on the Animal Welfare Web site at http://www.landfood.ubc.ca/ animalwelfare.

\section{REFERENCES}

Bach, A., C. Iglesias, and I. Busto. 2004. A computerized system for monitoring feeding behavior and individual feed intake of dairy cattle. J. Dairy Sci. 87:4207-4209.

Daniels, K. M., K. E. Webb Jr., M. L. McGilliard, M. J. Meyer, M. E. Van Amburgh, and R. M. Akers. 2006. Effects of body weight and nutrition on mammary protein expression profiles in Holstein heifers. J. Dairy Sci. 89:4276-4288.

DeVries, T. J., and M. A. G. von Keyserlingk. 2006. Feed stalls affect the social and feeding behavior of lactating dairy cows. J. Dairy Sci. 89:3522-3531.

DeVries, T. J., M. A. G. von Keyserlingk, D. M. Weary, and K. A. Beauchemin. 2003. Validation of a system for monitoring feeding behavior of dairy cows. J. Dairy Sci. 86:3571-3574.

Friend, T. H., C. E. Polan, and M. L. McGilliard. 1977. Free stall and feed bunk requirements relative to behavior, production and individual feed intake in dairy cows. J. Dairy Sci. 60:108-116.

Grant, R. J., and J. L. Albright. 1995. Feeding behavior and management factors during the transition period in dairy cattle. J. Anim. Sci. 73:2791-2803.

Huzzey, J. M., T. J. DeVries, P. Valois, and M. A. G. von Keyserlingk. 2006. Stocking density and feed barrier design affect the feeding and social behavior of dairy cattle. J. Dairy Sci. 89:126-133.

Huzzey, J. M., D. M. Veira, D. M. Weary, and M. A. G. von Keyserlingk. 2007. Prepartum behavior and dry matter intake identify dairy cows at risk for metritis. J. Dairy Sci. 90:3220-3233. 
Huzzey, J. M., M. A. G. von Keyserlingk, and D. M. Weary. 2005. Changes in feeding, drinking, and standing behavior of dairy cows during the transition period. J. Dairy Sci. 88:2454-2461.

Mulligan, F. J., P. J. Caffrey, M. Rath, J. J. Callan, P. O. Brophy, and F. P. O'Mara. 2002. An investigation of feeding level effects on digestibility in cattle for diets based on grass silage and high fibre concentrates at two forage:concentrate ratios. Livest. Prod. Sci. 77:311-323.

Murphy, M. R. 1992. Symposium: Nutritional factors affecting animal water and waste quality. Water metabolism of dairy cows. J. Dairy Sci. 75:326-333.
Nielsen, B. L. 1999. On the interpretation of feeding behaviour measures and the use of feeding rate as an indicator of social constraint. Appl. Anim. Behav. 63:79-91.

SAS Institute. 1999. SAS User's Guide. SAS Institute Inc., Cary, $\mathrm{NC}$

Tolkamp, B. J., D. P. N. Schweitzer, and I. Kyriazakis. 2000. The biologically relevant unit for the analysis of short-term feeding behavior of dairy cows. J. Dairy Sci. 83:2057-2068.

Vasilatos, R., and P. J. Wangsness. 1980. Feeding behavior of lactating dairy cows as measured by time-lapse photography. J. Dairy Sci. 63:412-416. 